\title{
The Prevalence of Melissococcus plutonius by Polymerase Chain Reaction in Kurdistan apiaries, Iran
}

\author{
Mohammad Khezri ${ }^{1,}$, Mojtaba Moharami ${ }^{2}$, Hussein Modirrousta ${ }^{2}$, Zahra Salahi ${ }^{2}$, \\ Babak Rokhzad ${ }^{1}$ \\ ${ }^{1}$ Veterinary Research Department, Agricultural and Natural Resources Research and Education Center, AREEO, Sanandaj, Iran \\ ${ }^{2}$ Department of Honeybee, Silkworm and Wildlife Research Disease, Razi Vaccine and Serum Research Institute, AREEO, Karaj, Iran
}

Email address:

khezri1836@gmail.com (M. Khezri)

${ }^{*}$ Corresponding author

\section{To cite this article:}

Mohammad Khezri, Mojtaba Moharami, Hussein Modirrousta, Zahra Salahi, Babak Rokhzad. The Prevalence of Melissococcus plutonius by Polymerase Chain Reaction in Kurdistan apiaries, Iran. Animal and Veterinary Sciences. Vol. 4, No. 6, 2016, pp. 93-96. doi: $10.11648 /$ j.avs.20160406.12

Received: July 12, 2016; Accepted: July 26, 2016; Published: December 14, 2016

\begin{abstract}
European foulbrood (EFB) is caused by bacterial agents Melissococcus plutonius and is considered of major importance because it can be spread through many bee products including honey, which is internationally widely traded. A polymerase chain reaction (PCR) molecular diagnosis survey for honey bee pathogen EFB was conducted on European honey bee (EHB), Apis mellifera, population sampled from Kurdistan apiaries $(\mathrm{n}=100)$. For multiplex PCR amplification of partial 16S rRNA (= SSU rRNA) gene fragments (486 bp), was conducted on 100 samples. Results showed that of 100 samples only 4 samples (4\%) were positive for M. plutonius in Kurdistan apiaries. This is the first study to document the occurrence of EFB by PCR assay in Kurdistan apiaries. It seems that surveys are required to characterize the distribution and prevalence of $M$. plutonius in different regions of Iran.
\end{abstract}

Keywords: M. plutonius, European foulbrood, PCR, Kurdistan apiaries

\section{Introduction}

Pollinators such as bee [1] have an important role in pollination process both to farming and to wild plant populations. The global value to agriculture alone was approximated at $€ 153$ billion in 2005 [2]. However, honeybee populations are menaced globally by a number of native and emerging diseases. It is important to figure out the epidemiology of pollinator disease to minimize the spread of disease in pollination and to favor provision. EFB disease is distributed worldwide [3] on all mainlands where Apis mellifera is kept and it also affects A. ceranae [4]. EFB is caused by the bacterium Melissococcus plutonius. This microorganism has been recognized as the pathogen that causes EFB in 1908 and it was named Bacillus $Y$ and later renamed Bacillus pluton [5]. Later the pathogen was reclassified as Melissococcus plutonius based on additional culture and chemical knowledge [6]. EFB is spread when larvae eat food that contains the bacteria M. plutonius [7].
There is evidence that transmission may occur from Varroa destructor [8]. When larva ingest food contaminated with $M$. plutonius, the bacterium multiplies in the anaerobic conditions of the larval midgut where it causes disease [9], where the bacteria that increase [5]. The extent of larval mortality was directly dependent on the period or on the number of bacteria that was fed to the larva, studies have shown that a strong correlation was established between the mortality of larvae that died from EFB and dose of $M$. plutonius organisms, in addition, a clear linear relationship exists between the time duration of feeding M. plutonius inoculated basic larval diet and larval mortality [9]. EFB is importance because it transmission capability through many bee products including honey is high and it can be easily spread because of the wide international traded [10]. The isolated can be identified and differentiated by means of simple tube agglutination tests, PCR, and hemi-nested PCR. M. plutonius can be isolated from larvae, adult bees and honey bee products [11]. Information cannot be presented on 
the recent history of EFB disease in Iran, including the geographical spread. The epidemiology of EFB isn't available in more detail in Iran. It is believed that EFB is present in most parts of Iran [12]. The aim of the present study was to determine the molecular prevalence and epidemiology of EFB in Kurdistan apiaries.

\section{Materials and Methods}

\subsection{Samples Collection}

Due to the protocol of the Iranian Veterinary Organization [13], sampling was done and 5\% of hives in each beekeeping center $(n=100)$ were investigated. Approximately 100 nurse bees are removed from combs from October 2014 to September 2015 in Kurdistan apiaries. Analysis of worker bees indicates that individuals from the brood nest contain more bacteria than bees from flight entrances; therefore, it was suggested that samples of bees are preferably collected from the brood nest [14], where the amount of M. plutonius in foragers equaled that found in nurse bees [3]. Samples were stored at $-20{ }^{\circ} \mathrm{C}$ until analyzed.

\subsection{Preparation of Samples for PCR and DNA Extraction}

DNA was extracted from samples using the High Pure PCR Template Preparation Kit (Takapozist, Tehran, Iran) according to the manufacturer's instructions. The procedure included several steps: Adult bees were placed in filter grinding bag. The grinding buffer was added: $0.5 \mathrm{ml}$ per bee and it was crushed, then $1.5 \mathrm{ml}$ of the supernatant were transferred to a $2 \mathrm{ml}$ Eppendorf tube. A "crude" centrifugation step was included for bigger volumes. The samples were centrifuged at 2,000 $\mathrm{g}$ for 10 minutes and then $1.5 \mathrm{ml}$ was transferred to an Eppendorf tube. They were centrifuged at 2,000 g for 2 minute and the supernatant was discarded. The DNA templates were directly used in a PCR or were store in $-20^{\circ} \mathrm{C}$ until needed.

\subsection{Multiplex Polymerase Chain Reaction}

For multiplex PCR amplification of partial 16S rRNA (= SSU rRNA) gene fragments (486 bp), first $50 \mu$ l reaction mixture contains 5 ng genomic DNA, $3 \mathrm{mM} \mathrm{MgCl}_{2}, 200 \mu \mathrm{M}$ of each deoxyribonucleotide triphosphate, $100 \mathrm{ng}$ of forward primers (EFB-F; 5-CTTTGAACGCCTTAGAGA-3) and reverse primer (EFB-R; 5-ATCATC TGTCCCACCTTA-3), 5 $\mu \mathrm{l}$ of $10 \times$ PCR buffer $(100 \mathrm{mM}$ Tris $/ \mathrm{HCl}, \mathrm{pH} 8.3 ; 15 \mathrm{mM}$ $\mathrm{MgCl}_{2} ; 500 \mathrm{mM} \mathrm{KCl}$ ) and $1 \mathrm{U}$ of Taq polymerase. Conditions of amplification consist of an initial denaturation cycle at $95^{\circ} \mathrm{C}$ for 2 minutes followed by 40 cycles of denaturation $\left(95^{\circ} \mathrm{C}, 30\right.$ seconds $)$, primer annealing $\left(61^{\circ} \mathrm{C}, 15\right.$ seconds), primer extension $\left(72^{\circ} \mathrm{C}, 1\right.$ minute) followed by additional extension step of 5 minutes at $72^{\circ} \mathrm{C}$ [11].

\subsection{Electrophoresis}

The PCR products and 100bp DNA ladder were then separated by electrophoresis on 1\% Agarose gel and stained with $0.5 \mu \mathrm{l} / \mathrm{ml}$ Ethidium bromide (100 volts for $1 \mathrm{~h}$ ) following UV Transilluminator. Documentation was done with Kodak (M12, Japan).

\section{Results}

All of 100 samples were investigated by PCR for $16 \mathrm{~S}$ rRNA (= SSU rRNA) of $M$. plutonius. Total infection prevalence in the Kurdistan apiaries with PCR test was $4 \%$ (Fig. 1).

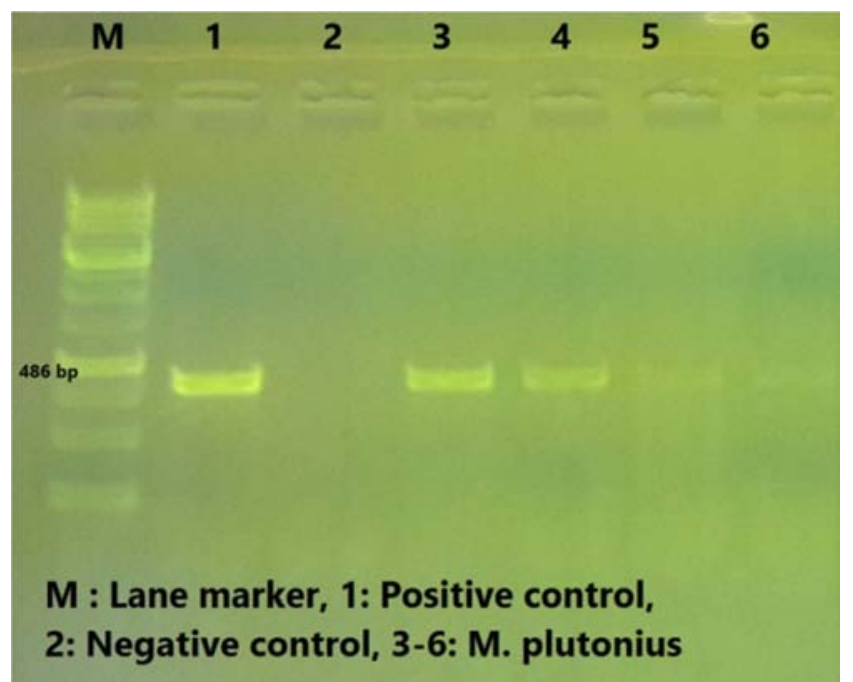

Figure 1. Electrophoresis results of $16 S$ rRNA (= SSU rRNA) gene fragments $(486 \mathrm{bp})$.

\section{Discussion}

EFB as having the tendency to stay inapparent, then to appear, sometimes in a very acute form, and then often to vanish impulsively, mostly after midsummer [5]. It spread has been reported from all continents of the world [6]. Some authors believe that lack of effective pollen was having an effect on the incidence of EFB [15]. Incidences of EFB have increased in recent years (Fig. 2) [16]. In some countries, PCR techniques were used to detect EFB in colonies with and without symptoms [17].

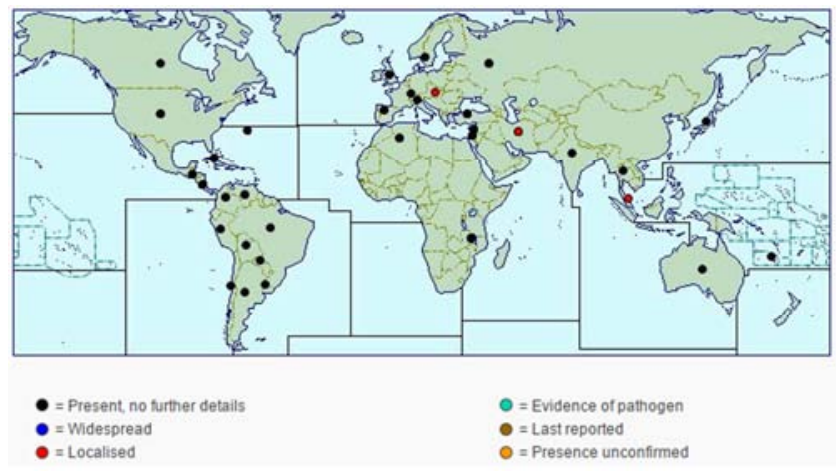

Figure 2. Distribution map of EFB in world [18]

The scenario of EFB varies in different countries. In one study in Iran with standard strain, PCR was developed and 
specific primers were used. Of 12 suspicious samples, eight samples were positive by PCR and 2 samples were positive by culture [19]. 195 honey bee samples in Hatay and Adana region of Turkey were investigated by selective media tests and the results showed $19 \%$ of samples were infected by $M$. plutonius [20]. In Saudi Arabia, two of 40 colonies of honey bees showed abnormal signs. Laboratory diagnosis of larvae and scales showed that the causative organism of EFB, $M$. plutonius, was present [21]. EFB was common in Baghdad, Anbar, Diyala, Babil and Tameem Governorates [22]. EFB has been reported in South Africa [23], Algeria, Libya, Morocco, Tunisia, Tanzania, Senegal and Guinea-Bissau [24]. In parts of England and Wales EFB and AFB are widespread and the system run is more complex for EFB than for AFB [25]. In Norway, EFB is a rare disease with the last verified case in 1980 , but in 2010 about 3000 colonies were destroyed and sampling in 2011 reveals that the bacterium is common and widespread there will be a change in the strategy to control the disease [26]. The Veterinary Authority with responsibility for reporting and control of diseases of honey bees has current knowledge, and authority over, all domesticated apiaries existing in the country or zone; EFB is modifiable in the whole country or zone, and any clinical cases suggestive of EFB are subjected to field and laboratory investigations. For the three years following the last reported isolation of the EFB agent, an annual survey supervised by the Veterinary Authority, with no positive results, have been carried out on a representative sample of apiaries in the country or zone to provide a confidence level of at least $95 \%$ of detecting EFB if at least $1 \%$ of the apiaries were infected at a within-apiary prevalence rate of at least $5 \%$ of the hives. Such surveys may be targeted towards areas with the last reported isolation of the EFB agent; to maintain free status. An annual survey supervised by the Veterinary Authority, with no positive results, is carried out on a representative sample of hives in the country or zone to indicate that there have been no new isolations; such surveys may be targeted towards areas with a higher likelihood of isolation [10]. Data on disease prevalence in Iran from the prioritized inspection service will be compared with unbiased data from 'random' apiaries study and they are still in progress. There was not implemented a strategy with the aim to eradicate $M$. plutonius from Iran apiaries. One of the strategies focused on several topics which, virulence of different M. plutonius strains, disease transfer within and among apiaries and efficacy of treatment with different drugs at the different time of the year were recognized as important.

\section{Acknowledgements}

Agricultural and Natural Resources Research and Education Center of Kurdistan supported this project (No: 453-18-93132). In addition, we thank Department of Honeybee, Silkworm and Wildlife Research Disease, Razi Vaccine and Serum Research Institute.

\section{References}

[1] Buchler, R., Andonov, S., Bienefeld, K., Costa, C., Hatlina, F., Kezic, N., Kryger, P., Spivak, M., Uzunov, A., and Wild, J. 2013. Standard methods for rearing and selection of Apis mellifera queens. standard methods for Apis mellifera research. Journal of Apicultural Research, 52.

[2] Gallai, N., Salles, J. M., Settele, J., and Vaissiere, B. E. 2009. Economic valuation of the vulnerability of world agriculture confronted with pollinator decline. Ecological Economics, 68, 810-821.

[3] Forsgren, E., Budge, G. E., Charriere, J.-D., and Hornitzky, M. A. Z. 2013. standard methods for Apis mellifera pest and pathogen research. Journal of Apicultural Research, 52, 1.

[4] FAO 2006. Honey bee diseases and pests: a practical guide. 8,33 .

[5] Bailey, L. 1983. Melissococcus pluton, the cause of European foulbrood of honey bees (Apis spp.). Journal of Applied Bacteriology, 55, 65-69.

[6] Bailey, L., and Collins, M. D. 1981. Reclassification of Streptococcus pluton in a new genus Melissococcus, as Melissococcus pluton nom. rev.; comb. nov. Journal of Applied Microbiology 53, 215-217.

[7] Shimanuki, H. 1997. Bacteria, in Honey Bee Pests, Predators, and Diseases R. A. Morse and K. Flottum, Editors. A. I. Root Company. 718.

[8] Kanbar, G., and Engels, W. 2003. Ultrastructure and bacterial infection of wounds in honey bee pupae punctured by Varroa mites. Parasitology Research, 90, 349-354.

[9] McKee, B. A., Goodman, R. D., and Hornitzcky, M. A. 2004. The transmission of European foulbrood (Melissococcus plutonius) to artificially reared honey bee larvae. Journal of Apiclutural Research, 43, 93-100.

[10] OIE 2015. Infection of honey bees with Meliisococcus plutonius (european foulbrood), in Terrestrial Animal Health Code. OIE.

[11] OIE 2008. European Foulbrood of Honey Bees, in OIE Terrestrial Manual 2008. OIE. 405-409.

[12] Ahmadi, A. A. 1984. Incidence of Honeybee Diseases and Parasites in Southern Iran. Bee World, 65, 134-136.

[13] Bokaie, S., Sharifi, L., and Mehrabadi, M. 2014. Prevalence and Epizootical Aspects of Varroasis in Golestan Province, Northern Iran. Journal of Arthropod-Borne Diseases, 8, 102-107.

[14] Roetschi, A., Berthoud, H., Kuhn, R., and Imdorf, A. 2008. Infection rate based on quantitative real-time $P C R$ of Melissococcus plutonius, the causal agent of European foulbrood, in honey bee colonies before and after apiary sanitation. Apidologie 39, 362-371.

[15] Herbert, E. W., and Shimanuki, H. 1984. An update on European foulbrood research in New Jersey. American Bee Journal, 124, 472-473.

[16] Forsgren, E., Lundhagen, A. C., Imdorf, A., and Fries, I. 2005. Distribution of Melissococcus plutonius in honeybee colonies with and without symptoms of European foulbrood. Microbial Ecology, 50, 369-374. 
[17] Belloy, L., Imdorf, A., Fries, I., Forsgren, E., Berthoud, H., Kuhn, R., and Charriere, J. 2007. Spatial distribution of Melissococcus plutonius in adult honey bees collected from apiaries and colonies with and without symptoms of European foulbrood. Apidologie 38, 136-140.

[18] Beverley, C. 2012. Improving lives by solving problems in agriculture and the environment. UK: CABI, Nosworthy Way, Wallingford, Oxfordshire.

[19] Moharami, M., Modirrousta, H., moeinfar, N., and Seddighi Khavidak, S. 2015. Rapid detection of Melissococcus Plotinus the agent of European foulbrood in honey bee colonies by PCR. 7, 3-8.

[20] Yalcinkaya, A., Keskin, N., and Özkirim, A. 2009. After colony losses in Hatay and Adana region of Turkey the investigation of honey bee diseases, in APImondia: Montpellier, France.

[21] El-Naga, A. M. A. 1987. Diagnosis of European foulbrood $(E F B)$ in Saudi Arabia. Arab Gulf Journal of Scientific Research, 5, 47-53.
[22] Sivaram, V. 2004. General status of Apiculture in Iraq. FAO Consultant for the Apiculture Project (Ministry of Agriculture - Government of Iraq).

[23] Govan, V. A., Brozel, V., Allsopp, M. H., and Davison, S. 1998. A PCR detection method for rapid identification of Melissococcus pluton in honeybee larvae. Applied Environmental Microbiology, 64, 1983-1985.

[24] Hussein, M. H. 2000. Beekeeping in Africa: I. North, East, North-East and West African countries. Apiacta, 1, 32-48.

[25] Wilkins, S., Brown, M., Andrew, A., and Cuthbertson, A. G. 2007. The incidence of honey bee pests and diseases in England and Wales. Pest Management Science, 63, 10621068.

[26] Dahle, B., Sorum, H., and Weidemann, J. H. 2011. European foulbrood in Norway: How to deal with a major outbreak after 30 years absence, in COLOSS Workshop: The future of brood disease research - guidelines, methods and development, Copenhagen: Denmark. 8. 